president of the Museums Association, the Castle Museum is a valuable addition to the all too scanty collections, which illustrate the past social life of England.

\section{Science and the Home}

THE great variety of material that the glass industry is now able to place at the disposal of the architect and the builder is well demonstrated by the 'Glass Hall' erected in the Daily Mail Ideal Home Exhibition at Olympia, which closes on April 30. The exhibits showed that in the hands of artistcraftsmen glass can be made a most effective medium of decoration. As regards the Glass House itself, the light-diffusing outer walls were made of fluted glass bricks permitting no observation from the outside. A partial vacuum inside renders them useful for the insulation as regards heat and sound. Each of the rooms of this house exhibits phases, useful and decorative, of the possibilities in glass, and the Crystal Kitchen has glass walls on two sides with the great merits of giving plenty of light and of being very easily kept clean. The Glass Train brought into Addison Road Station for the Exhibition, is, in a way, even more striking, as throughout it the walls, floors and ceilings are of glass. It is an exhibition in itself and includes examples of the 'Insulight' glass bricks mentioned above and of the Armour-plate glass, specially heat-treated so as to possess great fire-resisting properties with high mechanical strength. It can be bent through $30^{\circ}$ without breaking and will withstand a range of temperature from $-70^{\circ} \mathrm{C}$. to $+300^{\circ} \mathrm{C}$. The numerous fittings and other features represent nearly six hundred different varieties of glass. In another branch of industry the domestic possibilities of 'Staybrite' in pans, sinks, door furniture, toilet fittings and table-ware are demonstrated. The strength and wearing properties of this and similar materials must inevitably prove their superiority in the home. Then for the purpose of keeping food fresh and cool, one of the oldest principles for the production of long-sustained low temperature is employed in the 'Kepkold' series of coolers. By keeping the surrounding absorbent tiles supplied with water the cooling effects of evaporation are obtained without recourse to the more expensive refrigerators the utility of which depends on a supply of electricity or gas.

\section{Optical Projection of Surgical Operations}

AN optical apparatus of some interest to surgeons, devised by Profs. H. Costantini and L. Verain, of the University of Algiers, has recently been produced by the firm of Barbier Bénard and Turenne, 82 Rue Curial, Paris. It is termed a 'Scialyscope' and is a development of the shadowless light now installed in many operating theatres. It consists essentially of a conical reflector nearly $2 \frac{1}{2}$ metres in diameter, and of roughly parabolic form, by means of which the rays from a very powerful light-source are concentrated on the field of operation. Beneath the lamp itself is placed an optical system containing a large right-angled prism by which an image of the field of operation is formed on a translucent screen in an adjoining room. The magnification on the screen is $3 \frac{1}{2}$ diameters, and the illumination is so powerful that a spectator at a distance of seven metres can obtain a brilliant view of every detail in the field of operation. There has always been very great difficulty in demonstrating operative details to a group of students; their mere presence in an operating theatre is undesirable, and it is obviously impossible for most of them to obtain any but a fleeting glimpse of what is happening. With this apparatus forty or fifty students in an adjoining room can easily follow every detail, and it will be noted that their view is obtained from a point immediately above the field of operation. By means of a microphone and a loud speaker, the surgeon can describe to them at the same time all that is being done. The method would appear to have considerable possibilities and it certainly overcomes the difficulties involved in demonstrating operative details to a number of individuals.

\section{Report of the University of Birmingham}

IN his seventeenth and last report to the Council, presented at the annual meeting of the Court of Governors of the University, the Vice-Chancellor (Sir Charles Grant Robertson) gives a summary of the progress of the University during his tenure of office. In 1920 "the high hopes, the vaulting ambitions and the dreams of a golden dawn that inspired a Great Britain freed by the Armistice from the terrors and horrors of the War slowly faded away or were frozen out, and in their place came spiritual and moral anarehy and the cynicism derisive of the past, and baffled by the present, that fears nothing but the future". Since then the University has gone rapidly forward. The income and expenditure in 1921 were $£ 143,631$ and $£ 144,535$ respectively, while for 1937 they were $£ 232,690$ and $£ 230,805$, not taking into account the sums for fellowships, scholarships and other trust funds which pass through the accounts of the University. Assets have increased to $£ 2,199,306$, and the University is free from debt, the contribu. tions to the endowment since 1920 being not less than $£ 930,000$. The grants from local authorities have increased from $£ 11,887$ to $£ 33,570$. Expenditure in stipends has increased from $£ 34,131$ to nearly $£ 100,000$. There are now 34 full-time professors and 10 part-time, while the non-professorial staff now numbers 297. The Library grant has been quintupled and the number of readers and of books taken out has increased eightfold. "The function of a university library is not merely to satisfy existing needs, but to create new appetites as yet unknown and always unpredictable; you never can tell what may result from the contact of a young mind with an adequately equipped library. In a university more minds than we are aware of are always at flash-point. It is the spark that is so often wanting.'

Sir Charles notes with satisfaction the success which has attended the large measure of self-government which has been given to the undergraduates"the student body has justified the confidence that the unification of responsibility with power demands". $\mathrm{He}$ wishes, however, that a really serious share in 